\title{
First Tentative Conclusions on the early development of verb morphology*
}

\author{
Wolfgang U. Dressler - Marianne Kilani-Schoch - Dagmar Bittner \\ Wien - Lausanne - Berlin \\ dabitt@zas.gwz-berlin.de \\ Marianne.KilaniSchoch@efm.unil.ch \\ wolfgang.dressler@univie.ac.at
}

\section{Preliminaries}

In these conclusions we can deal only with some of the tentative comparative results of the workshop papers on the early development of verb morphology. The main focus is on criteria of how the child detects morphology and how this emerging morphological competence develops in its earliest phases. In view of the purpose and tentative character of these conclusions, all references will be limited to the papers of the workshop and to earlier studies by workshop participants within the "Crosslinguistic Project on Pre- and Protomorphology in Language Acquisition". Much more will be given in the projected final publication.

Although the papers have identified differences also in the premorphological predecessors of verbs, it is not yet clear whether these are only due to individual, personal differences of children and to the different onset of recordings (i.e. before or after the emergence of the earliest rote-learned verb forms) or also to cross-linguistic differences between the languages investigated. The latter possibility is rendered less probable by the assumption that typologically relevant morphological distinctions concern only morphological grammar and not extragrammatical operations, such as onomatopoetic reduplication (cf. Russian, Finnish, French, German, Lithuanian; Lithuanian reduplicated fillers are a later phenomenon).

The turning point of the children's detection of morphology is clearly well after the onset of all the project recordings. But the results are still provisional because of the small data-base of each language, i.e. the general restriction to just one or two children, the limited size of data for each child (with the exception of Lithuanian), and thus lack of control over individual intralingual variation. Still some generalizations can be proposed in hypothetical form.

We are going to present our tentative hypotheses in the following logical order:

1. emergence and development of mini-paradigms and other morphological relations which may induce the child to detect morphology.

2. morphological substitutions, analogies, overgeneralizations which may prove that a child has detected morphology.

3. questions of periodisation, based on these and other criteria, especially in reference to the demarcation of pre- vs. protomorphology.

4. generalities (candidates for universals) about the emergence of morphological categories.

5. possible typological differences, with specific reference to characteristics of the ideal inflecting vs. isolating language type.

6. outlook.

* Many thanks are due to all participants of the Berlin workshop, notably to Sabine Klampfer and Natalia Gagarina. 


\section{Mini-paradigms and other morphological relations}

The emergence of three true mini-paradigms (three-member paradigms), with the properties proposed in Kilani-Schoch \& Dressler (2001) and briefly repeated in our Introduction, has been accepted as a sufficient criterion for assuming that the child can detect morphology by relating these forms to each other. Particularly in case of small-sized corpora, we suppose that the child has produced many other true mini-paradigms which we have not been able to observe.

But is the emergence of three three-member paradigms a necessary criterion? This has been doubted in the contribution on Austrian German, with the counter-proposal that a greater number of two-member mini-paradigms may compensate for the lack of three-member miniparadigms, i.e. many two-member mini-paradigms may be sufficient evidence for the child's ability to generalise on morphological relations. In this case, the quantity of smaller miniparadigms would compensate for the lack of a greater number of members of paradigms. Only in this case, and provided that the other criteria for true mini-paradigms hold, twomember mini-paradigms would be more than just predecessors of true mini-paradigms.

The next question concerns the formal identification of mini-paradigm members. We decided to consider the early emergence of Russian Past.Sg.Masc. upal 'fell', Past.Sg.Fem. upal-a and Past.Pl. upal-i as predecessor of a, and not as a, true mini-paradigm, because only one, nonprototypical verbal subsystem is involved (with adjectival inflection for number and gender), whereas three members from a prototypical subsystem, such as 1.Sg.pres. kopaj-u 'I'm digging', 3.Sg. kopaj-et, 3.Pl. kopaj-ut, would suffice for establishing a true mini-paradigm.

Obviously, simpler relations are easier to analyse than complex ones. For example, the relation between Russ. Inf. kopa-t' 'dig' and past masc. kopa-l allows easier identification of the categories signalled by the two inflectional suffixes than is the case with the relation between the same Inf. kopa- $t^{\prime}$ and the 3.Sg.pres. kopa-j-et, where correct identification presupposes two segmentations (present-/close-stem-formation before agreement suffix) instead of one. When such oppositions are mastered, then double segmentation demonstrates greater capacities of the child than mere simple segmentation. But when we consider only emergence (not yet acquisition or mastery) of paradigm members, then both types of oppositions are on equal level, insofar as they show that the child uses forms whose comparison leads the child to segmentation and identification of any sort. In other words, word-based morphology should emerge earlier than stem- and root-based morphology (cf. below 4).

If the mini-paradigm is suppletive, as in French Inf. [metr] 'to put', Sg.pres. [me], past participle [mi], then first of all, this variation can induce the child only to identify morphosemantic oppositions but not recurrent morphotactic generalisations, whereas regular relations (whether productive or unproductive) are stimuli for detecting morphotactic relations as well (obviously we can hypothesise in our project on the children's organisation of morphology only via what we have sampled of their production).

Since suppletives are the first, or prominently among the first, true mini-paradigms in French, Spanish, Croatian, German, Lithuanian, Finnish and Maya, it seems as if morphosemantic oppositions are detected earlier than morphotactic ones. No true counterevidence is presented by Russian and English, since suppletive verbs play a smaller role in Russian morphology, and in view of the small size of the English samples studied here.

Mini-paradigms (in the strict sense) consist of different inflectional forms of the same lemma. Children may be stimulated, however, to engage in morphological segmentation and identification also by a looser version of "paradigms", i.e. sets of paradigmatically related forms of the same lexeme, i.e. of lemmas which differ only by prefixes or composition. Thus 
the roots and stem-forms are identical, and inflectional behaviour is identical as well. Therefore inflectional forms derived from same root with same stem formations should have very similar effects for inflectional analysis as those derived from the same lemma. Relevant instances have been found in German, Lithuanian and Russian, but not in similarly structured Croatian.

Of particular importance among lexemes, because of their morphosemantically systematic correlations, are aspectual pairs which differ only via prefixation (e.g. Russ. ipfv, risovat' 'to draw' vs. pfv. na-risovat', which occur only later). This property is shared by perfective (and semelfactive) suffixation in Croat., Russ. $-n u$-, although the respective perfective and correlated imperfective lemmas do not form a single lexeme. Also Lithuanian and Croatian negative prefixation (preverbal $n e$-) must be mentioned here. Note that in German, stressed and separable verbal prefixes (also called particles) emerge earlier than verbs themselves, thus when they occur as prefixes combined with verbs, segmentation is easy.

Relations established by other types of word-formation (i.e. verbal derivation) emerge later and thus appear to be of less importance for the detection of morphology.

Finally, we have to mention that the concept of mini-paradigms has further implications. A first hypothesis (discussed in Kilani-Schoch \& Dressler 2001) that the genesis and development of mini-paradigms may be linked to general conditions of uninflectibility in adult systems, has not been confirmed so far. But a second hypothesis by Bittner (this volume) appears to be more promising: meaning and syntactic use of components of protomorphological mini-paradigms appear to be different from those of members of complete paradigms in later, adult-like modularised morphology. This can even be deductively derived from the Saussurean thesis that the value (F. valeur) of a linguistic unit depends on the oppositions it enters within a system: children's first mini-paradigms involve less oppositions than complete, adultlike paradigms. Thus non-adultlike meanings and uses of inflectional forms in protomorphology may not be simply due to a transitional stage in syntactic or even cognitive development.

\section{Morphological substitutions}

Early substitutions which exhibit apparently free variation or other signs of lacking understanding of morphosemantics or of syntactic function, show lack of identification of the role of morphology. If it can be demonstrated that they are due to constructivist pattern selection, then they are highly relevant for our model of premorphology as in early Lithuanian 3.Sg. shifts and in the Berlin child's root infinitives.

For the purpose of our workshop papers, only later substitutions in protomorphology are significant, because they indicate detection of morphology.These substitutions are characterised by apparently adequate syntactic usage and apparent lack of gross deviations from adult morphological meaning.

Within our corpora, no case of inflectional imperialism has been found, not even in early Lithuanian 3.Sg. shifts.

All substitutions appear to be optional: whenever they have no counterexamples in adult-like ("correct") usage, then they are infrequent, therefore no reasonable decision can be made between optional or categorial (obligatory) character. This means that they appear to represent either errors of performance or instances of insecure competence. Thus the assumption of categorial modifications of the target system hinges on the assumption that "correct" forms 
may all be rote-learned, whereas substitutions derive from children's morphological creativity, independent of whether this could be assigned to performance or competence.

Some substitutions can be classified as simplification in whatever analysis, such as the omission of the German past participle prefix ge- in both German corpora (see also below 4).

Most substitutions are instances of analogical levelling, such as (Berlin and Vienna) German replacement of strong past participles by weak ones, or French, Spanish, Croatian and Finnish substitutions. Most of the examples have in common that they represent shifts from either unproductive to productive patterns, or from non-default to default, or from less to more transparent patterns (cf. 4 below).

With the exception of French, (Berlin and Vienna) German and rare Russian root infinitives, whose interpretation is notoriously problematic (cf. Katicic 1997), substitutions within protomorphology point again to the precedence of morphosemantic over morphotactic learning. But this may be an illusion which derives from the easier identification of nonidentity of children's productions with adult morphotactics than morphosemantics.

Finally we should mention that in the Russian data, analogical levelling occurs only later, after the onset of modularised morphology. A massive increase of such "errors" is reported for other project languages. These substitutions may be due to rule extraction, a matter beyond the scope of our papers.

\section{Periodisation}

All authors agree that the demarcation of pre- and protomorphology should hold for morphology at large, thus not separately for verbs vs. nouns, etc. This is what we expect in a model of subsequent modularisation of morphology first and of its submodules later. Of course, this cannot imply that mini-paradigms emerge everywhere at the same time, be it in productive vs. unproductive classes or in verbs vs. nouns (particularly if one subsystem is much richer than another one). The assumption is just that once children detect the morphological principles of segmentation and recurrence of form and meaning, they can apply them everywhere in morphology. As a consequence, other factors must be made responsible for early vs. late emergence of different morphological patterns.

All authors also agree that both emergence of mini-paradigms (1) and of morphologydetermined substitutions (2) are crucial for demarcation between pre- and protomorphology. But, intriguingly, the relative chronological order of emergence of each of these two crucial phenomena differs from language to language.

In the French, Maya and Finnish corpora, morphological substitutions emerge clearly later than true mini-paradigms, in Russian much later (only in the modularised stage). In the Berlin German and Spanish corpus, their first occurrence coincides with the emergence of true miniparadigms. In the Austrian German and Croatian corpora, substitutions emerge much earlier than true mini-paradigms: this has been for Austrian German - in addition to considerations of sample size - one reason for taking two-member paradigms (instead of three-member paradigms) into account (cf. 1). Thus the onset of the Austrian child's protomorphology coincides with a clear verb spurt and with the occurrence of first two-member mini-paradigms and the first overgeneralisations.

For many models of acquisition, the relation of morphological development to lexical and syntactic development is fundamental. If we start with lexical development, then a coincidence of the emergence of mini-paradigms with a lexical verb spurt has been found for the German, Spanish, Russian and Croatian children. For the Finnish, Lithuanian, Yucatec 
and the Lausanne children, no verb spurt has been found, but a steady cumulative increase of verb lemmas: also such development is compatible with a critical-mass account of the detection of morphology by the child, i.e. when (s)he disposes over a critical (or sufficient) mass of verb lemmas. Also if a verb spurt precedes the emergence of true mini-paradigms, as in the Lithuanian and Yucateco corpora, this is compatible with critical-mass hypotheses.

An additional possibility of relating the detection of morphology to lexical development is to measure increase in lexical diversity, as proposed by Klampfer (this volume).

A coincidence of the emergence of mini-paradigms with a syntactic spurt has been found with the German, Spanish, Croatian and, to a moderate degree, Russian children. With the French, English and Finnish children, a syntactic spurt has come first. Both chronological constellations are compatible with models which either subordinate morphological to syntactic development or assume interdependence between them.

\section{Some generalities about the emergence of morphologically expressed categories}

The following conclusions are very general and do not imply that morphosemantics of the categories are adult-like.

4.1. With regard to universal preferences we may repeat the old hypothesis that in general pragmatically/semantically less marked (i.e. cognitively less complex) categories or subcategories should be easier accessible for children and thus should emerge before respective marked ones or, if they emerge simultaneously, be significantly more frequent. In accordance with this prediction, in our data, within the category number, the less marked singular forms emerge before plural forms. Within the category of person, the less marked 1 st and 3 rd person indicative emerge (in different mutual orders) before the 2 nd person, but in the imperative, the less marked 2nd person emerges first (cf. Klampfer, Maillochon, Bassano \& Dressler 1999). But there is a double markedness reversal in the 2 nd Sg. Imperative: this form is less marked than both the 2nd Sg. Indicative and than the $3 \mathrm{rd} \mathrm{Sg}$. Imperative, and thus it emerges earlier. This latter relation can only be evidenced in languages like Turkish. In the languages compared here, weak support comes only from the 1 st Pl. Imperative which emerges, in form and/or meaning, a) later than the 2nd Sg. Imp. (but also because in the marked plural), b) earlier than the 1st and 2nd Pl. Indicative (because the 1st Pl. Imp. is also directed towards the interlocutor(s), thus combines both persons).

Also within the category tense, the less marked present (exception: Russian), within mood, the less marked indicative and imperative, and within voice, the less marked active emerge first.

Usually these phenomena of order of emergence can be explained in other ways as well. However this does not automatically throw out the markedness explanation, first because multiple explanation is normal in social and developmental phenomena, second no competing explanation would hold for all the asymmetries for which the markedness explanation holds.

4.2. Morphotactically transparent (and thus more iconic) verb forms should be preferred over opaque ones. In accordance with this prediction, German umlaut and ablaut verb modifications emerge later than fully transparent forms without them. In the other languages similar phenomena are vitiated by the disturbing variable of high input token frequency of opaque verb paradigms (e.g. suppletive 'to be'). 
Hence a more telling outcome of our prediction is the direction of substitutions. Thus, before modularised morphology, in our French, German, Spanish, Finnish and Croatian corpora, generally more transparent verb forms are substituted for less transparent ones, but not viceversa. For example, mathematically, in the partially riming verbs Fr. Inf. prendre, PP pris and rendre, PP rendu, analogical levellings of the past participle to either *prendu or *ris should be equally possible. However French-learning children typically produce prend $u$ but never ris.

The preference for high morphotactic transparency also predicts that word-based morphology should be preferred to stem-based and, especially, to root-based morphology. A striking support comes from Russian reduplicative root formations of the type beg-beg 'run-run' from Inf. beg-a-t', 3.Sg. beg-a-j-et (with stem-forming thematic vowel/a/), which emerge only in modularised morphology (cf. Gagarina 1997). This lateness of root morphology renders the assumption of early German root forms dubious (cf. Bittner, this volume, and Klampfer, this volume), as does phonological analysis as well.

4.3. On the parameter of indexicality (supported by the preference for optimal word shapes, i.e. for one-foot words), children start with the most natural solution of using only one affix. For example, the German language already approaches this unmarked option, insofar as no verb form has more than one inflectional suffix and unstressed true prefix. Only the PP (e.g. ge-spiel-t 'played', ge-schlaf-en 'slept') is more complex, i.e. more marked. According to this prediction, at the beginning, both the Berlin and the Vienna children often drop the prefix. Thus, Dressler and Klampfer, and Bittner also claim, against the literature, that this prefix dropping is not only a matter of phonology. The early samples of the other language corpora show as well lack of double affixation. The Russian exception of Past. Fem. $u-p a-l-a$, Pl. $u$ $p a-l-i$ 'fell' can be considered as spurious: a) the verb never occurs without the prefix in the corpus, b) non-past forms (root $/ \mathrm{pad} /$ ) emerges only later. Thus the child may not have analysed the sequence upal, identical with the form for Past. Masc. In other words, detection of morphology seems to work from the periphery, i.e. first detection of inflectional suffixation, only then of presuffixal stem formation.

4.4. Several of our languages have non-inflected base forms as iconic reflections of morphosemantic unmarkedness. Thus we can predict that these forms should either precede inflected forms or, if they emerge simultaneously, be more frequent. This prediction is borne out in the relevant oppositions of English, French, Spanish, Croatian, Lithuanian, Finnish and Yucateco Maya. Moreover, no clear counterexamples occur.

\section{Some typological assumptions}

Among cross-linguistic differences in the early emergence of verb forms we select the following which bear on the relative approximation of verb systems to the morphology-rich ideal inflecting vs. the ideal isolating type, which is devoid of inflectional morphology (cf. Introduction).

5.1. Morphological richness, thus heterogeneity, might induce children to be more selective in the forms they produce, whereas morphological poverty might render them less sensitive to morphological heterogeneity. In accordance with this hypothesis, the Russian child rarely confuses forms, whereas the German and Swiss French children do. But this would not explain why the Lithuanian and Spanish children have many early confusions or syncretisms. Moreover the Berlin child is less selective than the Vienna child and than the two Lausanne children. 
5.2. Another prediction linked to morphological richness seems more promising: due to the greater quantity of paradigm members in morphology-richer languages, in stronger inflecting languages mini-paradigms should emerge earlier and occur more frequently than in weaker inflecting languages. Earliness can be measured by the interval between first emergence of verbs vs. of mini-paradigms. This intervall is two months for the Russian child, but longer for the German, French, Spanish, Croatian children. That this intervall is slightly longer in the Lithuanian corpus is less disturbing than the much longer intervall in morphology-rich Finnish.

5.3. Homophony (but not biuniqueness, see Kilani-Schoch \& Dresssler 2000) has been proposed as a possible factor for favouring the emergence of verb forms in early phases of acquisition. Now, homophony plays a bigger role in weaker than in stronger inflecting languages. This would predict that infinitives emerge earlier when they are homophonous with other verb forms. This would explain the early emergence and frequent use of infinitives in French and German, as opposed to Croatian, Lithuanian, Finnish - but Russian is problematic.

The early emergence of base forms in French, Spanish, Croatian, Lithuanian and Finnish (cf. 4.4 ) is also explainable by the fact that many of them are homophonous or syncretistic.

\section{Outlook}

These conclusions are very tentative and present many more questions than answers. But we hope that they address interesting problems and approaches towards their solution. Finegrained acquisition studies of typologically both similar and very diverse languages such as the ones studied in this workshop appear to allow putting forward new questions or looking at old ones from a new perspective. Proceeding in our attempts to answer them is the purpose of the final publication of this workshop's papers. We intend to bring in more data, also from additional languages, to discuss them more deeply in the light of previous theoretical and empirical findings and to draw more elaborated and far-reaching comparative conclusions from a greater number of points discussed in the project papers on single languages.

\section{References}

Bittner, Dagmar (this volume): Early verb development in one German speaking child.

Gagarina, Natalia (1997): Aspektual'naja semantika i funkcionirovanije vidov russkogo glagola v detskoj reči. PhD thesis, Hercen State Pedagogical University of Russia, St. Petersburg.

Katičić, Antigone (1997): Zum Erstspracherwerb des Kroatischen: morphologische und syntaktische Aspekte beim Erwerb des Verbalsystems. MA thesis. University Wien.

Kilani-Schoch, Marianne / Wolfgang U. Dressler (2000): Are precursors of morphemes relevant for morphological theory? In: W.U. Dressler et al. (ed.), Morphological Analysis in Comparison. Amsterdam: Benjamins. pp. 89-111.

- (2001): The emergence of verb paradigms in two French corpora as an illustration of general problems of pre- and protomorphology. Munchen: Lincom. To appear.

Klampfer, Sabine (this volume): Early verb development in one Austrian child.

- / Isabelle Maillochon / Dominique Bassano / Wolfgang U. Dressler (1999/2000): On early acquisition of verb inflection in Austrian German and French: the case of person and number marking. Wiener linguistische Gazette 64-65. 1-29. 
